\title{
Basic Studies for Steelmaking by Physical Methods
}

\section{Zen-ichiro MORITA}

Sumitomo Metal Industries, Ltd.; Professor Emeritus, Osaka University, Fuso-cho, Amagasaki, Hyogo-ken, 660 Japan.

(Received on April 18, 1996; accepted in final form on July 15, 1996)

\begin{abstract}
Some examples of basic studies related to steelmaking by physical methods, which have been carried out by the author and his group, are described on the estimation of some physical properties of liquid metals, a new concept of network parameter for slags and fluxes and a new viscosity measurement for metallurgical melts.
\end{abstract}

KEY WORDS: steelmaking; viscosity; diffusivity; network structure; slag; flux.

\section{Introduction}

A number of studies have been made to obtain fundamental information on metallurgical substances and their reactions related to steelmaking by means such as thermodynamics, kinetics, transport phenomena, fluid dynamics and mathematical modelling. However, those concerned with the physical properties of melts and their application are relatively few in spite of their practical importance.

The author has been concerned with some basic studies on physical and chemical properties of liquid metals and slags related to steelmaking for some years. In this paper examples will be given concerning (1) the estimation of some physical properties of liquid metals by model theory, (2) a new concept of "network parameter" for slags and fluxes and (3) a new measuring technique for the viscosity of metallurgical melts. Their application to industrial practice will also be described.

\section{Estimation of Physical Properties of Liquid Metals Using Model Theory}

To obtain reliable information on physical and chemical properties, generally, it is essential to determine their accurate values by precise measurements. The measuring techniques have progressed remarkably and the accuracy of the measured values has obviously been improving. Nevertheless considerable discrepancies still exist in the data measured by each investigator at present as a result of experimental uncertainty. As an example, Fig. 1 shows the viscosity of liquid iron as a function of temperature, which is important for process analysis in steelmaking, ${ }^{1)}$ but it is very difficult to find out the most reliable value of the viscosity from the data in this figure.

In such a case it would be helpful to us in the course of the process analysis if we could estimate reliable values of physical properties of steel and slags theoretically or phenomenologically without undertaking experiments. Based on this concept the author and his colleagues have derived some simple formulae describing some physical properties of liquid metals and alloys. In this paper viscosity and diffusivity of liquid iron and some iron based alloys calculated using these formula are introduced.

\subsection{Estimation of Viscosity for Liquid Steel}

Assuming that the mechanism of viscosity of liquid

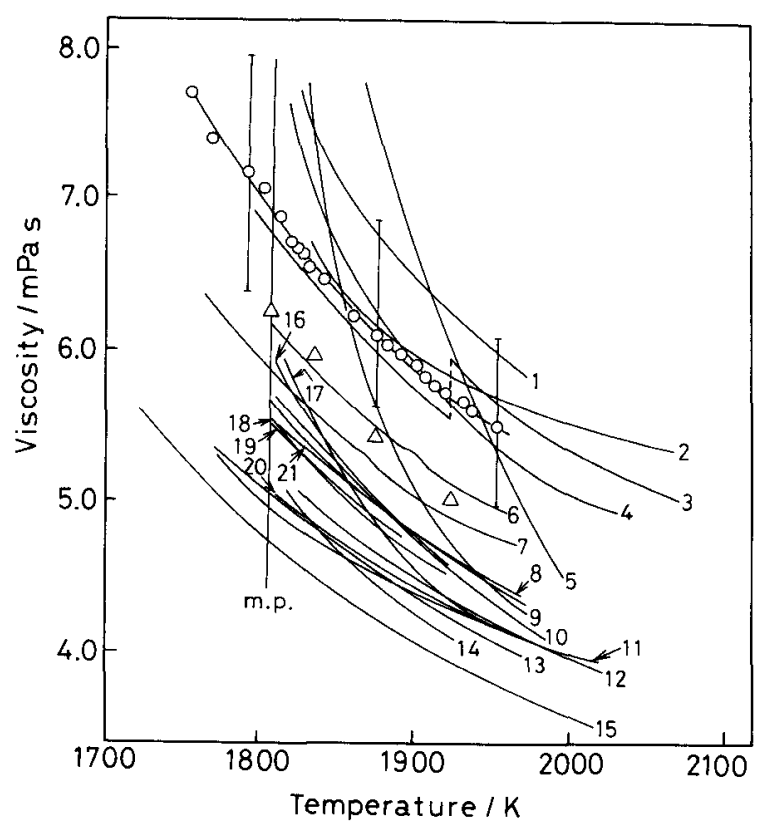

Fig. 1. Viscosity of liquid iron as a function of temperature. $O$ : Measured by Morita and Iida. ${ }^{5}$

$\triangle$ : Calculated using Eq. (1).

Identification numbers are: (1) Arsentiev et al., (2) Barfield and Kitchener, (3) Nobohatskii et al., (4) Romanov and Kochegarov, (5) Samarin, (6), (7) Ogino et al., (8) Nakanishi et al., (9) Vatolin et al., (10) Frohberg and Cakici, (11) Cavalier, (12) Saito and Watanabe, (13) Lucas, (14) Kawai et al., (15) Thiele, (16) Avaliani et al., (17) Wen Li-shi and Arsentiev, (18) Schenck et al., (19) Frohberg and Weber, (20) Narita and Onoe, (21) Krieger and Trenkler. (after Morita and Iida $^{5 y}$ ). 
metals is based on the momentum transfer to make the mass velocity uniform, the following expression has been derived for the viscosity of liquid pure metals ${ }^{2,3}$ )

$$
\begin{aligned}
& \eta \approx 4.5 g\left(r_{\mathrm{m}}\right)\left(1-r_{0} / r_{\mathrm{m}}\right) \frac{v_{0} P(T)_{\mathrm{m}}}{a} \ldots \ldots \ldots \ldots . . . \\
& P(T)=1-\int_{w}^{\infty} \frac{1}{\sqrt{2} \pi} \exp \left(-\frac{W^{2}}{2}\right) d w, \\
& W=\frac{\sqrt{3}}{2}\left(\frac{T_{\mathrm{b}}-T}{T}\right)
\end{aligned}
$$

where, $\eta$ : viscosity of liquid,

$g(r)$ : pair correlation function,

$r_{\mathrm{m}}, r_{0}$ : the position of first peak and its left-hand edge in the $g(r)$ curve,

$v_{0}$ : constant corresponding to the frequency of oscillation when no net displacement of the oscillating atom takes place,

$a$ : average interatomic distance,

$P(T)$ : probability function, and

$T_{\mathrm{b}}$ : boiling point.

Table 1 shows a comparison of calculated and observed values of viscosity of 19 kinds of liquid pure metals at their melting points, where $\eta_{\text {cal }}^{\text {a }}$ is the calculated viscosity by Eq. (1), $\eta_{\text {cal }}^{\mathrm{b}}$ that by using Andrade's empirical equation $^{4)}$ which has been a representative expression of viscosity near the melting point, and $\eta_{\text {obs }}$ observed viscosity,

It is obvious that calculated values using Eq. (1) are much closer to the observed values than the values calculated by Andrade's equation, and this fact shows that Eq. (1) can be effectively used to estimate the viscosity of liquid pure metals. The calculated values of viscosity for liquid iron by Eq. (1) are also shown in Fig. 1 with the measured values by the author's group. ${ }^{5)}$ The calculated values are a little lower than the author's measured values. Nevertheless this seems satisfactory

\begin{tabular}{|c|c|c|c|}
\hline \multirow{2}{*}{ Metal } & \multicolumn{3}{|c|}{ Viscosity (mPas) } \\
\hline & $\eta_{\text {cal }}^{\mathrm{a}}$ & $\eta_{\mathrm{cal} 1}^{\mathrm{b}}$ & $\eta_{\mathrm{obs}}$ \\
\hline $\mathrm{Na}$ & 0.68 & 0.62 & 0.70 \\
\hline $\mathrm{Mg}$ & 1.22 & 1.39 & 1.25 \\
\hline $\mathrm{Al}$ & 1.90 & 1.79 & $1.2-4.2$ \\
\hline $\mathrm{K}$ & 0.50 & 0.50 & 0.54 \\
\hline $\mathrm{Fe}$ & 6.37 & 4.55 & 6.92 \\
\hline $\mathrm{Co}$ & 5.93 & 4.76 & $4.1-5.3$ \\
\hline $\mathrm{Ni}$ & 5.64 & 4.76 & $4.5-6.4$ \\
\hline $\mathrm{Cu}$ & 4.07 & 4.20 & 4.34 \\
\hline $\mathrm{Zn}$ & 2.65 & 2.63 & 3.50 \\
\hline $\mathrm{Ga}$ & 2.00 & 1.63 & 1.94 \\
\hline $\mathrm{Ag}$ & 3.53 & 4.07 & 4.28 \\
\hline $\mathrm{Ln}$ & 1.97 & 1.97 & 1.80 \\
\hline $\mathrm{Sn}$ & 2.04 & 2.11 & 1.81 \\
\hline $\mathrm{Sb}$ & 2.23 & 2.68 & 1.43 \\
\hline $\mathrm{Au}$ & 5.50 & 5.80 & 5.38 \\
\hline $\mathrm{Hg}$ & 2.31 & 2.06 & 2.04 \\
\hline $\mathrm{Tl}$ & 2.55 & 2.85 & 2.64 \\
\hline $\mathrm{Pb}$ & 2.52 & 2.78 & 2.61 \\
\hline $\mathrm{Bi}$ & 2.13 & 2.54 & 1.63 \\
\hline
\end{tabular}

Table 1. Comparison of calculated and observed values for viscosity of liquid metals at their melting points. considering the uncertainly and discrepancy of the data reported by previous investigators.

On the other hand, the author and a colleague have derived another expression describing the viscosity of monoatomic liquids, such as metals, in terms of simple physical quantities by modifying Andrade's equation, as follows ${ }^{2}$ :

$$
\eta=1.8 \times 10^{-7} \frac{\left(M T_{\mathrm{m}}\right)^{1 / 2}}{V_{\mathrm{m}}^{2 / 3}} \cdot \frac{\exp \left(H_{\eta} / R T\right)}{\exp \left(H_{\eta} / R T_{\mathrm{m}}\right)} \text { (in SI unit) }
$$

where, $M$ : atomic weight, and

$V_{\mathrm{m}}$ : molar volume at melting point.

The calculated values by this equation agree well with measured values for metals whose melting points are rather low, but not with those for metals having higher melting points.

It would be helpful if those concerned with steelmaking practice could estimate the probable values of viscosity for molten steel and slags by simple calculations. From this standpoint the author and his colleague further derived some formulae expressing viscosity of liquid alloys. ${ }^{3,6,8)}$ The details of these formulae are omitted here because of space limitation. The calculated viscosity of liquid $\mathrm{Fe}-\mathrm{C}$ alloy, as an example, is compared with the experimental data in Fig. 2 and it is obvious the calculated result seems consistent with the experimental ones.

The viscosity of a multi-component dilute alloy, such as steel, $\eta$, can be evaluated by the following equation which can also be theoretically valid. ${ }^{2)}$

$$
\eta=\eta_{\mathbf{M}}+\sum_{i} \Delta \eta_{i}
$$

where, $\eta_{M}$ : viscosity of liquid pure metal $M$, and

$\Delta \eta_{i}$ : change of viscosity due to component $i$ in liquid $\mathrm{M}-i$ dilute binary alloy.

These expressions can be applied to estimate the viscosity of liquid steel. After a series of studies by the author's group, new formulae estimating the vis-

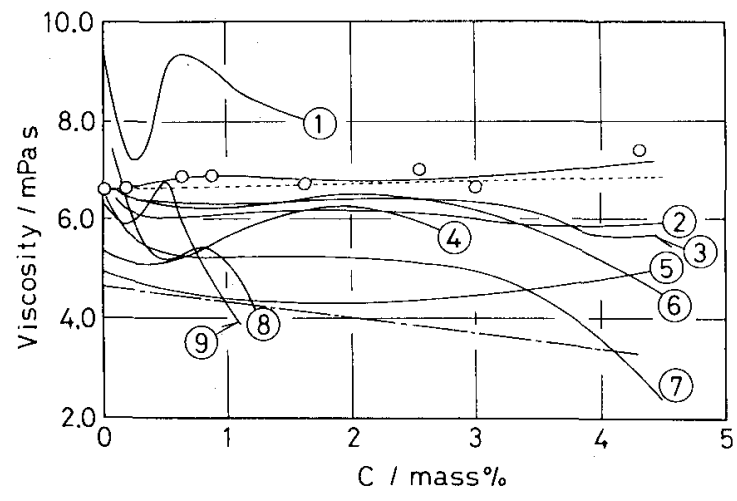

Fig. 2. Viscosities of liquid $\mathrm{Fe}-\mathrm{C}$ alloys at $1823 \mathrm{~K}$. 0 measured by Morita and Iida ${ }^{5 \text { ) }}$ ....-. calculated by Iida and Morita ${ }^{21}$ - - calculated by Hirai ${ }^{8)}$

(1) Arsentiev et al., (2) Vostryakov et al., (3) Turovskii, Lyubimov, (4) Krieger, Trenkler, (5) Lucas, (6) Barfield, Kitchener, (7) Vatolin et al., (8) Krasheninnikov, Filippov, (3) Wen Li-shi, Arsentiev. 
Table 2. Comparison of calculated and observed values of solute diffusivity in liquid iron at $1873 \mathrm{~K}$.

\begin{tabular}{ccc}
\hline Solute & $\begin{array}{c}\text { Calculated } \\
\times 10^{9} \mathrm{~m}^{2} \mathrm{~s}^{-1}\end{array}$ & $\begin{array}{c}\text { Observed } \\
\times 10^{9} \mathrm{~m}^{2} \mathrm{~s}^{-1}\end{array}$ \\
\hline $\mathrm{C}$ & 4.8 & $4.0-20$ \\
$\mathrm{Si}$ & 6.0 & $2.5-12$ \\
$\mathrm{Mn}$ & 4.6 & $3.5-20$ \\
$\mathrm{P}$ & 7.4 & 2.5 \\
$\mathrm{~S}$ & 8.7 & $4.5-20$ \\
$\mathrm{O}$ & 8.5 & $2.5-20$ \\
$\mathrm{H}$ & 150 & $80-200$ \\
$\mathrm{~N}$ & 12 & $6-20$ \\
$\mathrm{Ni}$ & 4.2 & $4.5-5.6$ \\
$\mathrm{Co}$ & 4.2 & $3.5-5.0$ \\
$\mathrm{Cr}$ & 4.3 & $3.0-5.0$ \\
$\mathrm{Al}$ & 8.6 & 10 \\
$\mathrm{~V}$ & 4.4 & $4.0-5.0$ \\
$\mathrm{Mo}$ & 2.6 & $3.8-4.1$ \\
\hline
\end{tabular}

cosity of liquid metals and ionic melts were proposed by $\mathrm{Hirai}^{8)}$ and $\mathrm{Du}$ Sichen et al. ${ }^{9)}$ Their formulae are also useful in estimating the viscosity of metallurgical melts.

\subsection{Estimation of Solute Diffusivity for Liquid Steel}

It is known that there is a close relation between viscosity and diffusivity. ${ }^{10)}$ This suggests that it may be possible to estimate the probable value of diffusivity when the viscosity value is definite. Based on this idea, we derived some formulae expressing self and solute diffusivity of liquid metals and alloys. ${ }^{2)}$ The calculated values of diffusivity of various solute elements in liquid iron at $1873 \mathrm{~K}$ are compared with their measured values in Table 2, and it is obvious that the calculated values are consistent with the measured ones.

\section{Network Parameter for Slags and Fluxes}

Since some kinds of liquid slags and fluxes have a so-called network structure their viscosity values will be higher than those for hypothetical melts of the same composition but without a network structure. This is due to the structure having a mass effect on the viscosity as a flow unit. Consequently we defined a "network parameter $\psi$ " which can reflect the magnitude of this network structure of slags and fluxes quantitatively ${ }^{11)}$ :

$$
\psi=\log \left(\frac{\eta}{\eta_{0}}\right)^{2} \approx \log \frac{M^{*}}{M}
$$

where $\eta$ is the viscosity of melts experimentally obtained, $\eta_{0}$ is the viscosity of hypothetical melts having no network structure which can be calculated by Eq. (2). $M$ and $M^{*}$ are the mass of flow unit respecting with and without network structure. Therefore when $\eta$ is known we can determine the value of $\psi$ by Eq. (4). Then, we investigated the network parameter of some slags related to steelmaking, and found that rather simple relations would exist between the network parameter and the lattice energy, the optical basicity and the sulphide capacity of slags, as shown in Figs. 3, 4 and 5.

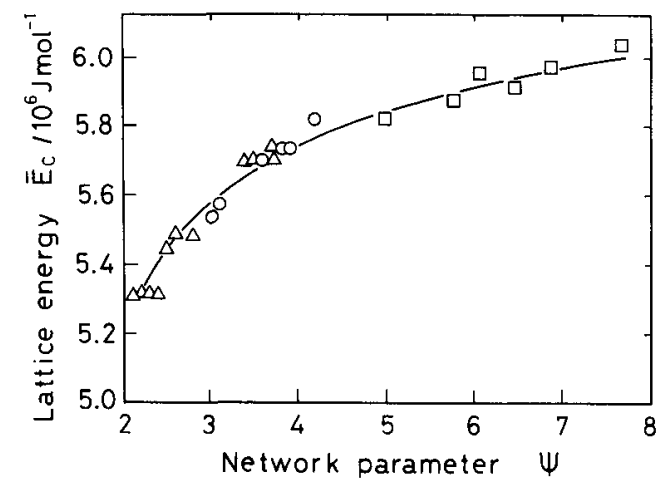

Fig. 3. Relationship between network parameter and lattice energy for molten slags at $1773 \mathrm{~K}$.

$\bigcirc \mathrm{CaO}-\mathrm{SiO}_{2}, \triangle \mathrm{CaO}-\mathrm{MgO}-\mathrm{SiO}_{2}, \square \mathrm{Al}_{2} \mathrm{O}_{3}-\mathrm{MgO}-$ $\mathrm{SiO}_{2}$

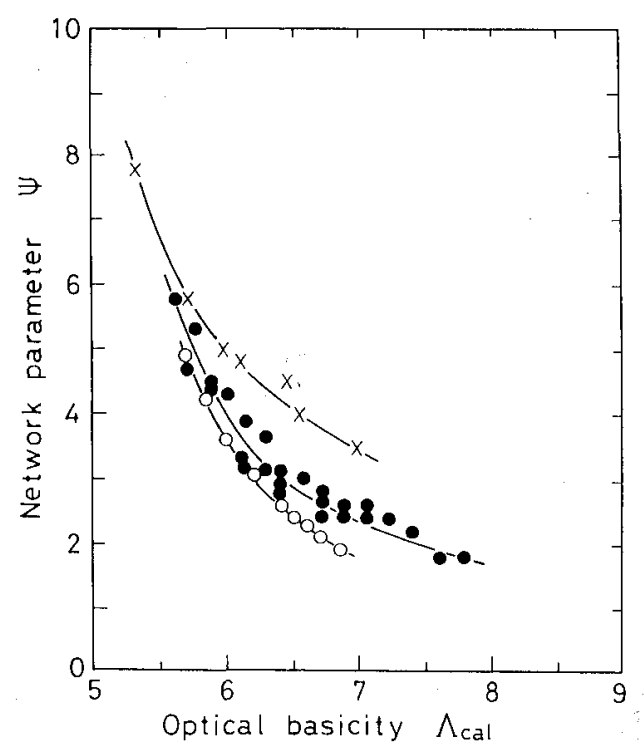

Fig. 4. Relationship between network parameter and optical basicity for molten slags at $1773 \mathrm{~K}$

$\bigcirc \mathrm{CaO}-\mathrm{SiO}_{2}, \odot \mathrm{CaO}-\mathrm{Al}_{2} \mathrm{O}_{3}-\mathrm{SiO}_{2}, \times \mathrm{SiO}_{2}-\mathrm{BaO}$

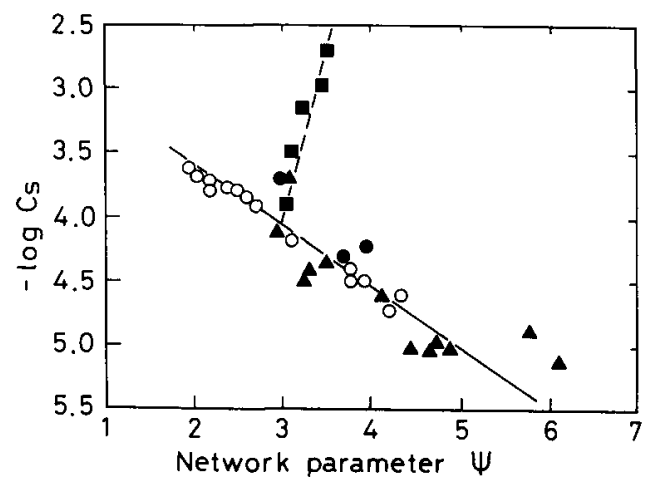

Fig. 5. Relationship between network parameter and sulphide capacity for molten slags at $1773 \mathrm{~K}$.

$\bigcirc \mathrm{CaO}-\mathrm{SiO}_{2}, \bullet \mathrm{CaO}-\mathrm{Al}_{2} \mathrm{O}_{3}-\mathrm{SiO}_{2}, \boldsymbol{\mathrm { CaO }}-\mathrm{MnO}$ $\mathrm{SiO}_{2}, \triangle \mathrm{CaO}-\mathrm{Al}_{2} \mathrm{O}_{3}-\mathrm{SiO}_{2}-\mathrm{MgO}$

\section{Oscillating-plate Viscometer}

The author and his group developed an oscillatingplate viscometer to measure the viscosity of high temperature melts instantaneously and continuously. ${ }^{12-14)}$ Figure 6 shows a schematic diagram of an oscillatingplate viscometer originally made by the author's group. 


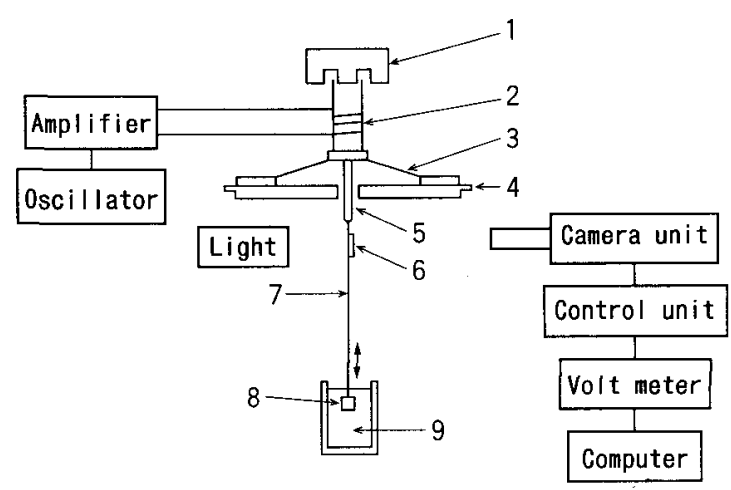
1. Magnet
2. Coil
3. Damper
4. Water
5. connecter
6. Target
7. Rod
8. Osc-plate
9. Sample

Fig. 6. Schematic diagram of an oscillating-plate viscometer.

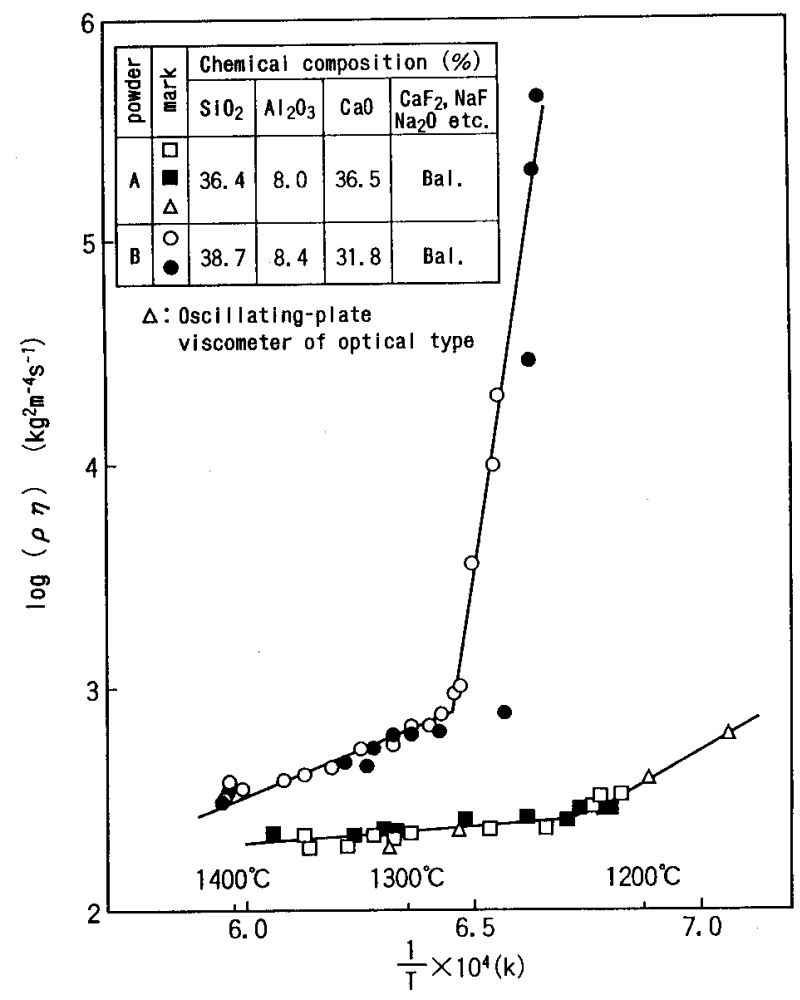

Fig. 7. Variation of $\log (\rho \eta)$ with temperature.

The viscosity measurement is based on the principle that when a plate is sinusoidally oscillated in a liquid the amplitude of the oscillating plate changes depending on the viscosity of the liquid, and the viscosity can be determined by the following equation.

$$
\rho \eta=k\left(\frac{E_{\mathrm{a}}}{E}-1\right)^{2}
$$

where $\rho$ is the density of melt, $\eta$ is the viscosity of melt, $E_{\mathrm{a}}$ and $E$ are the amplitude of oscillating-plate in the air and in the melt, respectively, and $k$ is the instrumental constant determined experimentally.

It has become possible to detect rapidly and continuously the change of viscosity of melts undergoing chemical reaction using this viscometer. This instrument can be used for both academic measurements of viscosities on a laboratory scale and plant scale measurements of viscosities of mold powders used in continuous casting and slags or fluxes in the steelmaking practice. Figure 7 shows an example of the measured values of viscosity for mold flux ${ }^{15}$ ) in which the viscosity and the solidification temperature are measured instantaneously. These values provide us useful information for the continuous casting operation.

\section{Summary}

Examples of studies related to steelmaking by physical methods were given concerning the estimation of viscosity and diffusivity of liquid metals, the new concept of "network parameter" for slags and fluxes, and the new oscillating plate viscometry for metallurgical melts.

\section{REFERENCES}

1) T. Iida and R. I. L. Guthrie: The Physical Properties of Liquid Metals, Oxford Science Publications, New York, (1988).

2) T. Iida and Z. Morita: Proc. Third Int. Iron and Steel Congress, Amer. Soc. Metals, Ohio, (1978), 104

3) T. Iida, Z. Morita and R. I. L. Guthrie: Can. Metall. Q., 27 (1988), 5.

4) E. N. Andrade: Phil. Mag., 17 (1934), 497, 692.

5) Z. Morita and T. Iida: Proc. First Sino-Japanese Symp. on Iron and Steel, Chinese Soc. Metals, Beijing, (1981), 103.

6) T. Iida, M. Ueda and Z. Morita: Tetsu-to-Hagané, 62 (1976), 1169.

7) Z. Morita, T. Iida and M. Ueda: Liquid Metals Conf. Ser. No. 30, Inst. of Physics, Bristol and London, (1976), 600.

8) M. Hirai: Tetsu-to-Hagané, 78 (1992), 399.

9) Du Sichen, J. Bygden and S. Seetharaman: Metal and Mater. Trans. B, 25B (1994), 519

10) W. Sutherland: Phil. Mag., 9 (1905), 781.

11) T. Iida, Z. Morita, K. C. Mills and T. Mizobuchi: Proc. Third Int. Conf. on Molten Slags and Fluxes, Inst. of Metals, London, (1988), 199

12) Z. Morita, T. Iida, M. Kawamoto and A. Mohri: Tetsu-toHagané, 70 (1984), 1242.

13) T. Iida, M. Kawamoto, S. Fujimoto and Z. Morita: Tetsu-toHagané, 71 (1985), 1490.

14) T. Iida, M. Kawamoto and Z. Morita: Nihon Kinzoku Gakkai Kaihou, 24 (1985), 410.

15) Y. Tamura, K. Yasumoto, K. Gunji, Z. Morita, T. Iida and M. Kawamoto: Tetsu-to-Hagané, 71 (1985), S1005. 